\title{
When partisan identification and economic evaluations conflict: a closer look at conflicted partisans in the United States
}

Article

Accepted Version

De Geus, R. ORCID: https://orcid.org/0000-0003-3053-2123 (2019) When partisan identification and economic evaluations conflict: a closer look at conflicted partisans in the United States. Social Science Quarterly, 100 (5). pp. 1638-1650. ISSN 1540-6237 doi: https://doi.org/10.1111/ssqu.12662 Available at https://centaur.reading.ac.uk/100268/

It is advisable to refer to the publisher's version if you intend to cite from the work. See Guidance on citing.

Published version at: https://doi.org//10.1111/ssqu. 12662

To link to this article DOI: http://dx.doi.org/10.1111/ssqu.12662

Publisher: Wiley

All outputs in CentAUR are protected by Intellectual Property Rights law, including copyright law. Copyright and IPR is retained by the creators or other copyright holders. Terms and conditions for use of this material are defined in the End User Agreement.

www.reading.ac.uk/centaur 
Central Archive at the University of Reading

Reading's research outputs online 


\title{
When partisan identification and economic evaluations conflict: a closer look at conflicted partisans in the United States
}

\begin{abstract}
Objective: most partisan voters in the US hold biased perceptions of the state of the national economy. Comparatively little is known however about voters who hold economic evaluations that conflict with their partisan identification. Methods: I use the American National Election Studies from 1980-2016 to conduct over time regression analyses of the identity and behaviour of conflicted partisans. Results: the share of conflicted partisans is substantial, especially during economic recessions. Conflict is associated with weak levels of party identification, higher levels of non-voting and lower levels of in-party voting. Conclusion: a closer look at conflicted partisans suggests that partisan bias in economic judgments fluctuates over time and varies amongst party affiliates. The study further shows that conflict between party affiliation and economic judgments is associated with differential voting and turnout patterns among party identifiers.
\end{abstract}


Partisan identification and economic evaluations are two key predictors of vote choice in Presidential elections in the United States (Campbell et al. 1960; Green, Palmquist, and Schikler 2002; Campbell 2005; Gerber and Huber 2010; Becher and Donnelly 2013; Lewis-Beck 1988, 2006; Lewis-Beck and Nadeau 2011; Duch and Stevenson 2008). An extensive body of work has shown that partisan identification and economic evaluations are strongly linked (Bartels 2002; Evans and Andersen 2006; Evans and Pickup 2010; Pickup and Evans 2013; Enns, Kellstedt, and Mcavoy 2012; Tilley and Hobolt 2011). Partisan identification may bias evaluations of the state of the economy in a variety of ways. Partisanship may act as a perceptual screen through which economic information is processed (Bartels 2002; Bullock et al. 2015; Gaines et al. 2007) or as a shield that prevents the consumption of information that contradicts party preferences (Taber and Lodge 2006; Lodge and Taber 2013; Iyengar and Hahn 2009). Partisan identification may also affect the attribution of blame and reward for economic outcomes (Tilley and Hobolt 2011). Regardless of the exact causal pathway, and all may operate at the same time, all paths lead to the same outcome: for the majority of the electorate, evaluations of the national economy align with party affiliation.

The alignment of partisan identification and economic evaluations has raised concerns about the accountability function of elections (Achen and Bartels 2016). As traditional accounts of retrospective voting stipulate, voters use their judgments of governing performance, such as evaluations about the state of the national economy, to decide whether or not to extend the mandate of the incumbent (Fiorina 1981; Key 1966; Healy and Malhotra 2013). If voters' ability to evaluate governing performance is hampered, in this case because a party affiliation distorts the interpretation of economic 
facts, then the accountability mechanism breaks down. Party bias hereby jeopardizes the quality of democratic governance (Achen and Bartels 2016).

The topic of partisan bias has received extensive examination in the academic literature (Lodge and Taber 2013; Taber and Lodge 2006; Tilley and Hobolt 2011; Bartels 2002; Bullock et al. 2015). This is understandable given the concerns it raises with regards to democratic accountability. Yet, the emphasis on partisan bias ignores the fact that not all voters who identify with a political party experience the same level of bias. It seems likely that as the strength of partisan affiliation decreases, the potential for bias decreases too. What is more, recent studies of partisan identification and economic perceptions suggest that the level of partisan bias is dependent on the economic context (Parker-Stephen 2013; Chzhen, Evans, and Pickup 2014; Dickerson 2016). Although voters have a desire for consistency, and hence align their party identification and economic evaluations, voters also have a desire for accuracy of their decisions and opinions (Lavine, Johnston, and Steenbergen 2012). If information about the economy is consistently negative, conflicting signals become more difficult to ignore (Parker-Stephen 2013).

Taken together this suggests that there is a segment of the electorate that identifies with a political party but simultaneously evaluates the economy in a non-biased, or less biased, manner. This introduces the potential for conflict between party identification and economic evaluations. Voters who experience such conflict are the focus of this paper; I explore the size, composition and behaviour of what I refer to as "conflicted partisans" within the American electorate. 
I use the American National Election Studies, covering the period from 1980 until 2016 to show that the percentage of conflicted partisans is substantial, with up to $25 \%$ of the electorate, or up to $80 \%$ of one of the partisan groups reporting economic evaluations that contradict their partisan preferences. I further find that the share of conflicted partisans varies strongly across election years and is associated with the strength of an individual's partisan identification. Finally, I find that there is a negative association between conflict and turnout as well as in-party voting.

\section{Conflicted Partisans}

It is well established that partisan preferences bias economic evaluations (Bartels 2002; Evans and Andersen 2006; Evans and Pickup 2010; Pickup and Evans 2013; Enns, Kellstedt, and Mcavoy 2012; Tilley and Hobolt 2011). This insight has cast doubt on the rational voter paradigm and the assumption that voters use elections to retrospectively punish and reward incumbents in response to their stewardship of the national economy (Key 1966; Fiorina 1981). Yet, recent works by Dickerson (2016) as well as by Chzhen, Evans, and Pickup (2014) and Parker-Stephen (2013) provide a different perspective. These studies explore how economic context shapes the relationship between partisan identification and economic evaluations. The authors find that the effect of partisan bias on economic evaluations is reduced in times of economic recession because voters are exposed to consistently negative cues about the economy. These insights are important because they suggest that levels of partisan bias are not fixed, but rather fluctuate. Furthermore, these findings suggest that, at least in some elections, a group of voters may hold economic evaluations that do not align with their partisan affiliations. 
The idea that partisan voters face conflicting signals is not new. Seminal studies of voter behaviour already spoke of cross-pressured partisans, referring to partisan voters whose party identification conflicted with other social identity groups they were a part of (Lazarsfeld, Berelson, and Gaudet 1944; Berelson, Lazarsfeld, and McPhee 1954; for a recent example see Brader, Tucker, and Therriault 2014). More recently, studies have shown that conflict may emerge not only due to various social identifications, but also between party affiliation and issue positions. Work by Hillygus and Shields (2008) shows for instance that some partisan voters hold issue positions that contradict the issue positions of their party, such as pro-life Democrats. Furthermore, work by Lavine and colleagues on ambivalent partisans shows that many partisans experience internal conflicts about their party, they find that up to $30 \%$ of partisan voters harbour a range of likes and dislikes toward their party, candidate and policies (Basinger and Lavine 2005; Lavine 2001; Lavine, Johnston, and Steenbergen 2012). These studies thus show that the partisan electorate is more heterogeneous than is oftentimes assumed.

Yet, voters who hold evaluations of the national economy that contradict their partisan preferences remain under-studied. ${ }^{1}$ This paper focuses on these voters and is structured around three, straightforward, empirical questions: how many conflicted partisans are there? Who are the conflicted partisans? And how do conflicted partisans behave at election time? Drawing on existing work I expect that the share of conflicted partisans will be highest when there is a clear period of economic downturn, such as in the case of an economic recession (Parker-Stephen 2013). Building on work on partisan

\footnotetext{
${ }^{1}$ Note that the work of Basinger 2005, Lavine 2012, Lavine 2001 on ambivalent partisans does include a measure of economic evaluations, but it combines this measure with opinions and likes and dislikes across seven other domains such as party traits, evaluations of party leaders, foreign and social policy and opinions on demographic groups. All these dimensions are then aggregated to combine into one measure of ambivalence.
} 
bias, which shows that partisans with strong levels of identification are most biased (Taber and Lodge 2006), I expect an inverse relationship between the strength of party affiliation and the likelihood of non-aligning economic judgments amongst party identifiers. I further expect that there is a negative association between conflict and voting as well as between conflict and voting for the party with which one identifies (Lavine, Johnston, and Steenbergen 2012; Brader, Tucker, and Therriault 2014).

\section{Data}

I use the ANES cumulative file 1948-2012, to which I have added the 2016 pre- and postelection survey. ${ }^{2}$ The data is thus a repeated cross-section. The analysis covers only the period 1980-2016 since one of the key variables, evaluations of the state of the national economy, was not included in surveys prior to 1980. Economic evaluations are operationalized using the standard retrospective question about the state of the national economy. Partisan identification is operationalized using a 7-point party identification scale. Only true independents are excluded. Full question wording is available in the online Appendix that accompanies this paper.

A partisan respondent is classified as conflicted when their evaluation of the state of the national economy conflicts with their partisan affiliation. For example, this may be a Republican partisan identifier who provides a positive evaluation of the economy under a Democratic President, or a negative evaluation under a Republican President. ${ }^{3}$

\footnotetext{
${ }^{2}$ Note the ANES file does not include the years 2006 and 2010.

${ }^{3}$ Note that in the surveys, respondents evaluate the state of the national economy in the preelection survey and thus evaluate the performance of the incumbent President. Thus, in the 2004 survey respondents evaluate the performance under President George W. Bush, not President Barack Obama.
} 


\section{Results}

The total number of respondents in the cumulative file from 1980-2016 is 35,797. Averaged across all years, approximately 50\% identifies with the Democratic Party, 37\% identifies as Republican and 12\% identifies as Independent, approximately $1 \%$ of respondents do not provide an answer to this question. These numbers are relatively stable across years although some variation occurs. In the analyses below Independents are excluded but party leaners are included. Figure 1 below shows the percentage of partisan identifiers that can be classified as conflicted in each of the election years under study. The conflicted partisans are split into either Democratic or Republican identifiers.

A few things stand out from Figure 1. First, the percentage of conflicted partisans varies strongly over the years, but is substantive at times. The years 1980, 1990, 1992, 2002 and 2008 stand out, with more than $60 \%$ of either Democratic or Republican partisans classified as conflicted in these years. The highest percentage of conflicted partisans is in 2008 with a total of $86 \%$ of Republican identifiers reporting negative economic evaluations under the Bush Presidency. This amounts to approximately $25 \%$ of the total electorate in that year. ${ }^{4}$ This aligns with the expectation that the share of conflicted partisans will be greatest in years of clear negative economic performance.

Second, in the majority of cases, the percentage of Republicans that are conflicted is higher than the percentage of conflicted Democrats. This may be explained by the fact that the sample includes nine Republican Presidents and seven Democratic Presidents. Furthermore, a greater number of Republican Presidents presided over economic

\footnotetext{
${ }^{4}$ This calculation includes Independents.
} 
recessions compared to Democratic Presidents (specifically 1990-1992, and 2008). A third observation from Figure 1 is that negative opinions about the economy under an inparty President are more frequent than positive opinions under an out-party President.

\section{Figure 1 here}

The second question I explore is: who are the conflicted partisans? As mentioned, it seems likely that there is a relationship between the strength of an individual's party affiliation and their likelihood of experiencing conflict. Averaged across years, approximately $28 \%$ of party identifiers have a "party leaning", $35 \%$ have a "weak" affiliation and $37 \%$ states they have a "strong" affiliation with one of the two major parties. Figure 2 offers a visual depiction of a simple cross-tabulation of the strength of party affiliation amongst both conflicted and non-conflicted partisans using the entire pooled sample.

Figure 2 illustrates that strong partisan identifiers are over-represented amongst non-conflicted partisans (39\%) whereas weak identifiers are the modal group amongst conflicted partisans (40\%). As expected, strong identifiers are under-represented amongst conflicted partisans $(30 \%)$ and the inverse is true for those with a party leaning who only constitute $27 \%$ of non-conflicted partisans. A chi-square test confirms that there is a significant association between the strength of party affiliation and conflicting economic evaluations. ${ }^{5}$ The association between partisan affiliation and conflicting economic evaluations is in line with expectation; those with strong levels of party identification are under-represented amongst the conflicted partisans. Yet, it is weak partisans, as opposed

\footnotetext{
${ }^{5}$ Provided in the Appendix, Table A2, Chi-Square test significant at $\mathrm{p}<0.000$
} 
to those with a mere party leaning, who are over-represented amongst the conflicted partisans. Although the group is small, there is a group of voters who identify strongly with a party and hold conflicting evaluations of the economy; they constitute only $6 \%$ of the entire partisan electorate.

\section{Figure 2 here}

For a more comprehensive test of the association between strength of party affiliation and the likelihood of conflicting economic judgments I run a pooled logistic regression model with a binary dependent variable Conflicted. The dependent variable takes the value of 1 if a partisan identifier is classified as conflicted and takes the value of 0 when partisan identification and economic evaluations align. As control variables I include a range of demographic variables that are known to be related to partisanship, these are: age, gender, ethnicity, education, strength of partisanship and political knowledge. Strength of partisanship consists of the three categories: leaning, weak and strong. Political knowledge consists of two categories: high and low. For the knowledge question respondents were asked whether they knew which party held the majority in the House prior to the elections. The model includes fixed effects for region and election year. ${ }^{6}$ I include an interaction term between strength of party affiliation and election year

\footnotetext{
${ }^{6}$ Note that the Appendix also presents the results using an alternative modeling strategy using a random effects specification for the election years as opposed to the dummy variable strategy used here. These estimates are available in Table A4. The results presented here are robust to this alternative strategy, with the exception that the random effects model suggests that those identifying as Black or Hispanic are less likely to experience conflict compared to those identifying as white.
} 
to allow for the fact that the importance of strength of party affiliation may vary across elections.

The full model estimates are available in the online Appendix, Table A3. The model estimates suggest that the likelihood of conflict is correlated with both the strength of someone's party affiliation as well as the particular election year. Using the model estimates I calculate the predicted likelihood of conflict for leaning, weak and strong party identifiers, displayed below in Figure 3. These calculations confirm the main conclusions drawn above. With the exception of 1980, respondents with a strong affiliation to their party are the least likely to experience conflict. Those with weak levels of affiliation are at times more likely to experience conflict (1980, 1982, 1984, 1986, 1992, 1996, 1996, 1998, 2008, 2012, 2016) and at times less likely to experience conflict $(1988,1990,1994,2000,2004)$ when compared to those with a mere party leaning. ${ }^{7}$

The fact that those with weak levels of identification are often more likely to report economic evaluations that conflict with their partisan preferences when compared to those with a mere party leaning may be explained along the lines of the theory of Zaller (1992), which suggests that the process of changing beliefs consists of an interaction between awareness and resistance. Partisans with weak levels of identification might have higher levels of awareness compared to party leaners, but lower levels of resistance compared to strong partisans, and hence be most prone to receive and absorb information that contradicts their partisan preferences.

\section{Figure 3 here}

\footnotetext{
${ }^{7}$ Differences between weak versus leaners and strong versus leaners are significant in all years apart from 2002.
} 


\section{Voting and Non-Voting Behaviour}

The final question that I explore is whether conflicted partisans behave differently at election time when compared to non-conflicted partisans. Here I focus exclusively on Presidential election years. I explore both whether conflicted partisans are less likely to vote on election day, and, when they vote, whether they are more likely to vote for the out-party (the party they do not identify with).

In terms of non-voting, the number of respondents who provided a response to this question over the course of the entire period 1980-2016 is 24,131 , for these respondents the voter turnout rate is $80 \%$ compared to a non-voting rate of $20 \%$. Thus, as is a common feature of election surveys, there is an over-reporting of voting rates in the sample. Turning now to the association between voting and conflict between party affiliation and economic evaluations I find that amongst partisans who are not conflicted the turnout rate is $84 \%$, compared to a slightly lower turnout rate of $80 \%$ among those who hold evaluations of the economy that contradict their party affiliation.

To provide a more complete test of this association I run a pooled logistic regression model of Presidential election years with a dependent variable that takes the value of 1 if a respondent indicated they did not vote (i.e. abstention), and the value of 0 if a respondent did vote. I include fixed effects for election year and geographic region and include a set of controls that are known to predict voting: age, gender, ethnicity, education, strength of party affiliation and political knowledge. I include an interaction term between conflict and election year to allow the experience of conflict to vary across time. The complete model estimates are provided in the online Appendix, Table A5. I 
here present the predicted likelihood (0-1) of abstention for conflicted and non-conflicted partisans across Presidential elections in the period 1980-2016 in Figure 4.

As can be seen from Figure 4, the general probability of non-voting is low, between $0.15-0.20$, in line with the proportions of non-voters reported above. Conflicted partisans have a higher likelihood of non-voting in the majority of election years under study (six out of ten). The difference in predicted likelihood is statistically significant in all Presidential election years under study with the exception of 1984. The substantive differences are small in most years, with the exception of the most recent election in which the probability of not voting was 0.11 points higher (out a $0-1$ range) for partisans who held conflicting economic evaluations. From this I conclude that conflicted partisans have a higher likelihood of not-voting compared to non conflicted partisans, but as Figure 4 shows, this may vary across election years.

\section{Figure 4 here}

In a second step I explore vote choice in Presidential elections in the period 19802016. In the period under study a total of $14 \%$ of respondents voted for the "out-party" (the party the respondent did not identify with) or for a third party, whereas the large majority, $86 \%$ voted for the party they identified with. ${ }^{8}$ The majority of out-party votes were cast by party leaners (42\%) and weak party identifiers (43\%), with only a very small proportion of strong party identifiers voting for the party they did not identify with; only $15 \%$ of all out-party votes were cast by strong identifiers. If I dis-aggregate this for

\footnotetext{
${ }^{8}$ Out of 14,703 responses over the entire cross-section. Also see Figure A1 in the online Appendix.
} 
conflicted and non-conflicted partisans I find that only $6.4 \%$ of non-conflicted partisans voted for the out-party or a third party, compared to $21 \%$ of conflicted partisans who did so. Of these conflicted partisans $40 \%$ identified as a party-leaner, $45 \%$ identified as a weak partisan and only $15 \%$ identified as a strong partisan identifier, illustrating the connection between the strength of party affiliation and the propensity of conflict as well as an out-party vote.

To explore the association between conflict and vote choice in Presidential elections I run a pooled binary logistic regression model whereby the dependent variable takes the value of 1 when a respondent votes for the "in-party", the party the respondent identifies with and the value of 0 if a respondent voted for the out-party or a third party. Note that non-voters are excluded from this analysis. ${ }^{9}$ The model includes fixed effects for election year and geographic region. It further includes the following control variables: age, gender, ethnicity, education level, strength of party affiliation and political knowledge. I also include an interaction between election year and conflict to allow the association between conflict and vote choice to vary across years. The full results of this model are provided in the online Appendix, Table A7 and suggest a negative association between conflicted partisanship and the probability of voting for the party one identifies with.

To interpret the substantive effects I present the predicted likelihood that a conflicted, versus a non-conflicted, partisan voted for their in-party, the party they identified with, in Figure 5. Conflicted partisans are significantly less likely to vote for

\footnotetext{
${ }^{9}$ The Appendix, table A8 provides a multinomial logit model that tests the effect of an in-party vote versus an out-party vote as well as a vote for a third party or abstention. The substantive results are the same as reported here. The Appendix also provides a model specification with random as opposed to fixed effects for election years, again the substantive associations are the same. This model is provided in Table A7 in the Appendix.
} 
the in-party across all years under study when compared to non-conflicted partisans. ${ }^{10}$ The likelihood of an in-party vote ranges between $85-95 \%$ for a non-conflicted partisan, compared to $70-95 \%$ for a conflicted partisan. Across the elections under study the contradiction between economic evaluations and partisan identification is associated with a reduction of the likelihood of an in-party vote of between 1 to 20 percentage points.

Because of the strong association with strength of party affiliation I re-estimate the vote choice model for each of the partisan identifier groups separately (leaners, weak identifiers and strong identifiers). These model estimates are provided in the online Appendix, Table A10. I find substantively similar associations between conflict and outparty voting amongst leaning and weak affiliates, but substantively much smaller and at times non- statistically significant associations amongst strong partisans. This suggests that it is mostly party leaners and those with weak affiliations to the party that drive the out-party voting pattern of conflicted partisans.

\section{Figure 5 here}

\section{A closer look: panel data on conflicted partisans}

The over-time analyses of conflicted partisans offer an overview of the size of this segment of the electorate as well as their behaviour, but these analyses have several limitations. Most importantly, the over-time data only provides snapshots of partisan voters at a certain point in time. It is possible however that partisan voters update their party affiliation in response to negative economic developments to avoid the very conflict

\footnotetext{
${ }^{10}$ Differences in predicted likelihoods are statistically significant across all survey years at $\mathrm{p}<$ 0.000 .
} 
that is of interest here. This cannot be captured by the over time data. To explore this option further I use two panel studies (ANES 1990-1992 and 2000-2004) to confirm that partisan identifiers update their economic evaluations without updating their partisan affiliation.

As expected, partisan identification is highly stable over time in both panel studies. In the 1990-1992 panel $(\mathrm{N}=985), 80 \%$ of respondents who identified with the Republican Party in the 1990 survey wave did so again in 1992. The same is true for $86 \%$ of Democratic identifiers. In the $2000-2004$ panel $(\mathrm{N}=748), 91 \%$ of respondents who identified as Republican in the 2000 survey wave did so again in the 2004 wave, and $89 \%$ of Democratic identifiers remain loyal to the party in both the 2000 and the 2004 wave. This suggests that respondents are unlikely to alter their party affiliation in-between survey waves.

Table 1 displays the economic judgments of partisan voters who self-identify with the same party in both waves of the panel. This suggests that voters' evaluations of the economy change whilst their party affiliation remains constant. This confirms that the majority of party affiliates are not updating their party identification in light of economic changes, but rather that changes in the state of the economy pose a potential conflict to party identifiers. The best example of this are Republican identifiers in the years 19901992. In $199033 \%$ of Republican identifiers disapproved of George H.W. Bush's handling of the economy, this disapproval increases with 20 percentage points by 1992 amongst Republican identifiers. Respondents thus update their economic judgments whilst maintaining their identification with their party. 


\section{Table 1 here}

\section{Conclusion}

An extensive body of work explores how partisan identification biases evaluations of the national economy, yet surprisingly little is known about voters who hold economic evaluations that contradict their partisan preferences. This paper has focused on this segment of the American electorate to illustrate the heterogeneity that exists amongst party identifiers. The study has shown that partisans who hold judgments of the national economy that do not align with their party identification constitute a substantive part of the electorate, especially in times of economic recession. Furthermore, the findings suggest that there is a negative association between conflict and voting, as well as inparty voting in Presidential elections.

The paper has sought to shed light on an under-studied segment of the American electorate and has shown that partisan voters as a group are not as homogeneous as is sometimes assumed. Although the majority of partisan voters hold economic evaluations that align with their partisan preferences, this is not true for all partisan voters. Further study of conflicted partisans may increase our understanding of the heterogeneous nature of party identifiers as well as help to explore conditions under which partisan bias is especially prevalent and when it is not. This would further shed light on the severity of the threat that partisan bias poses to democratic accountability and the conditions under which bias might be reduced. 


\section{References}

Achen, Christopher, and Larry Bartels. 2016. Democracy for Realists: Why Elections Do Not Produce Responsive Government. Princeton University Press.

Bartels, Larry M. 2002. "Beyond the Running Tally: Partisan Bias in Political Perceptions." Political Behavior 24 (2): 117-150.

Basinger, Scott J., and Howard Lavine. 2005. "Ambivalence, Information, and Electoral Choice.” The American Political Science Review 99 (2): 169-184.

Becher, Michael, and Michael Donnelly. 2013. "Economic Performance, Individual Evaluations, and the Vote: Investigating the Causal Mechanism." Journal of Politics 75 (4): 968-979. https://doi.org/doi:10.1017/S0022381613000959.

Berelson, Bernard, Paul Lazarsfeld, and William McPhee. 1954. Voting: A Study of Opinion Formation in a Presidential Campaign. Chicago: University of Chicago Press.

Brader, Ted, Joshua A. Tucker, and Andrew Therriault. 2014. "Cross Pressure Scores: An Individual-Level Measure of Cumulative Partisan Pressures Arising from Social Group Memberships.” Political Behavior 36 (1): 23-51. https://doi.org/10.1007/s11109-013-9222-8.

Bullock, John G., Alan S. Gerber, Seth J. Hill, and Gregory A. Huber. 2015. "Partisan Bias in Factual Beliefs About Politics." Quarterly Journal of Political Science 10 (4): 519-78.

Campbell, Angus, Philip E. Converse, Warren E. Miller, and Donald E. Stokes. 1960. The American Voter. New York; London: John Wiley.

Campbell, J.E. 2005. "The Fundamentals in US Presidential Elections: Public Opinion, the Economy and Incumbency in the 2004 Presidential Election." Journal of Elections, Public Opinion and Parties 15 (1): 73-83.

Chzhen, Kat, Geoffrey Evans, and Mark Pickup. 2014. "When Do Economic Perceptions Matter for Party Approval?: Examining the Endogeneity of Economic Perceptions Before and During the Economic Downturn.” Political Behavior 36 (2): 291-313. https://doi.org/10.1007/s11109-013-9236-2.

Dickerson, Bradley. 2016. "Economic Perceptions, Presidential Approval, and Causality: The Moderating Role of the Economic Context." American Politics Research 44 (446): 1037-1065. https://doi.org/10.1177/1532673X15600787.

Duch, Raymond M., and Randolph T. Stevenson. 2008. The Economic Vote: How Political and Economic Institutions Condition Election Results. New York; Cambridge: Cambridge University Press.

Enns, Peter K, Paul M Kellstedt, and Gregory E Mcavoy. 2012. "The Consequences of Partisanship in Economic Perceptions.” Public Opinion Quarterly 76 (2): 287310. https://doi.org/10.1093/poq/nfs016.

Evans, Geoffrey, and Robert Andersen. 2006. "The Political Conditioning of Economic Perceptions." The Journal of Politics 68 (1): 194-207.

Evans, Geoffrey, and Mark Pickup. 2010. "Reversing the Causal Arrow: The Political Conditioning of Economic Perceptions in the 2000-2004 U.S. Presidential Election Cycle." The Journal of Politics 72 (04): 1236-1251. https://doi.org/10.1017/S0022381610000654.

Fiorina, Morris. 1981. Retrospective Voting in American National Elections. Yale University Press. 
Gaines, Brian J., James H. Kuklinski, Paul J. Quirk, Buddy Peyton, and Jay Verkuilen. 2007. "Same Facts, Different Interpretations: Partisan Motivation and Opinion on Iraq." The Journal of Politics 69 (4): 957-974.

Gerber, Alan S., and Gregory A. Huber. 2010. "Partisanship, Political Control, and Economic Assessments.” American Journal of Political Science 54 (1): 153-173. https://doi.org/10.1111/j.1540-5907.2009.00424.x.

Green, Donald, Bradley Palmquist, and Eric Schikler. 2002. Partisan Hearts and Minds: Political Parties and the Social Identities of Voters. Yale University Press.

Healy, Andrew, and Neil Malhotra. 2013. "Retrospective Voting Reconsidered." Annual Review of Political Science 16 (1): 285-306. https://doi.org/10.1146/annurevpolisci-032211-212920.

Hillygus, Sunshine D., and Todd G. Shields. 2008. The Persuadable Voter: Wedge Issues in Presidential Campaigns. Princeton and Oxford: Princeton University Press.

Iyengar, Shanto, and Kyu S. Hahn. 2009. "Red Media, Blue Media: Evidence of Ideological Selectivity in Media Use.” Journal of Communication 59: 19-39. https://doi.org/10.1111/j.1460-2466.2008.01402.x.

Key, V.O. 1966. The Responsible Electorate: Rationality in Presidential Voting 19361960. Harvard University Press.

Lavine, Howard. 2001. "The Electoral Consequences of Ambivalence Toward Presidential Candidates.” American Journal of Political Science 45 (4): 915-929. https://doi.org/10.2307/2669332.

Lavine, Howard, Christopher D. Johnston, and Marco R. Steenbergen. 2012. The Ambivalent Partisan: How Critical Loyalty Promotes Democracy. New York; Oxford: Oxford University Press.

Lazarsfeld, Paul, Bernard Berelson, and Hazel Gaudet. 1944. The People's Choice: How the Voter Makes up His Mind in a Presidential Campaign. London; New York: Columbia University Press.

Lewis-Beck, Michael S. 1988. Economics and Elections. The Major Western Democracies. Ann Arbor - Michigan: University of Michigan Press.

- 2006. "Does Economics Still Matter? Econometrics and the Vote." The Journal of Politics 68 (1): 208-212.

Lewis-Beck, Michael S., and Richard Nadeau. 2011. "Economic Voting Theory: Testing New Dimensions." Electoral Studies 30 (2): 288-294. https://doi.org/10.1016/j.electstud.2010.09.001.

Lodge, Milton, and Charles S. Taber. 2013. The Rationalizing Voter. Cambridge University Press.

Parker-Stephen, Evan. 2013. "Tides of Disagreement: How Reality Facilitates (and Inhibits) Partisan Public Opinion.” The Journal of Politics 75 (4). https://doi.org/10.1017/S0022381613000789.

Pickup, Mark, and Geoffrey Evans. 2013. "Addressing the Endogeneity of Economic Evaluations in Models of Political Choice.” Public Opinion Quarterly 77 (3): 735-754. https://doi.org/10.1093/poq/nft028.

Taber, Charles S., and Milton Lodge. 2006. "Motivated Skepticism in the Evaluation of Political Beliefs." American Journal of Political Science 50 (3): 755-769.

Tilley, James, and Sara B. Hobolt. 2011. "Is the Government to Blame? An Experimental Test of How Partisanship Shapes Perceptions of Performance and Responsibility." 
The Journal of Politics 73 (2): 316-330. https://doi.org/10.1017/S0022381611000168.

Zaller, John. 1992. The Nature and Origins of Mass Opinion. Cambridge: Cambridge University Press. 


\section{Figures and Tables}

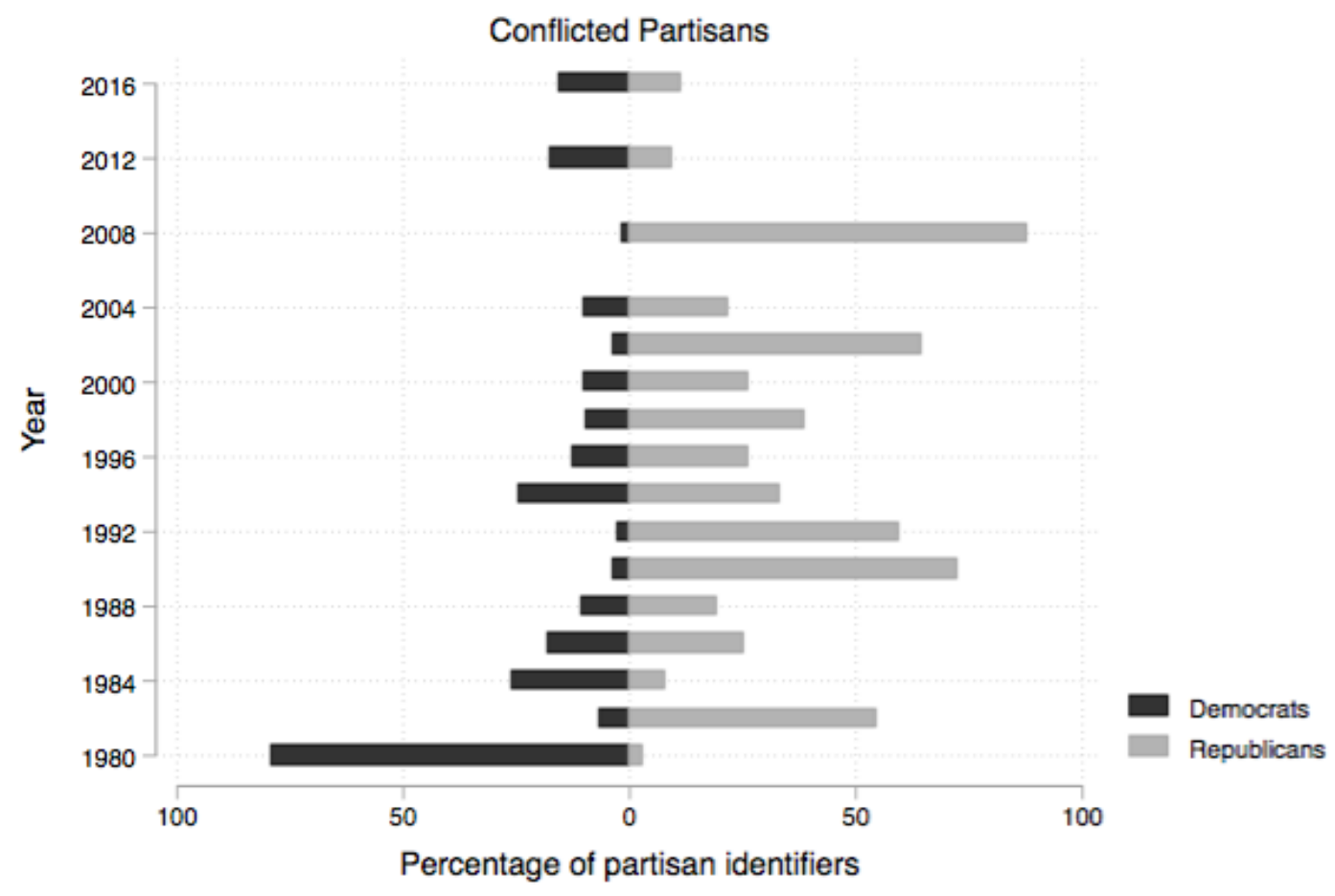

Figure 1 - Percentage of Conflicted Partisans Across Survey Years 


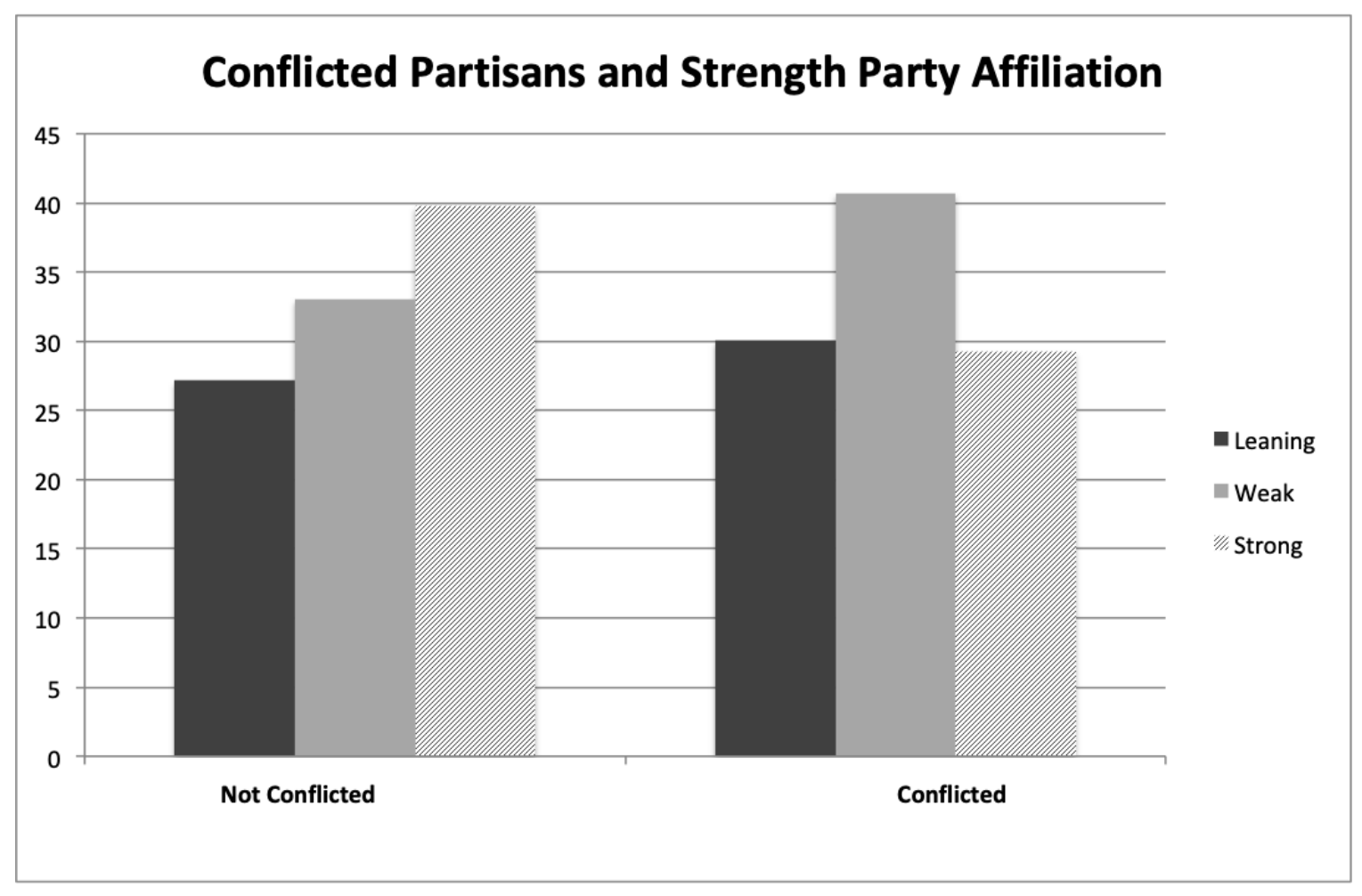

Figure 2 - Conflicted Partisans and Strength of Party Affiliation

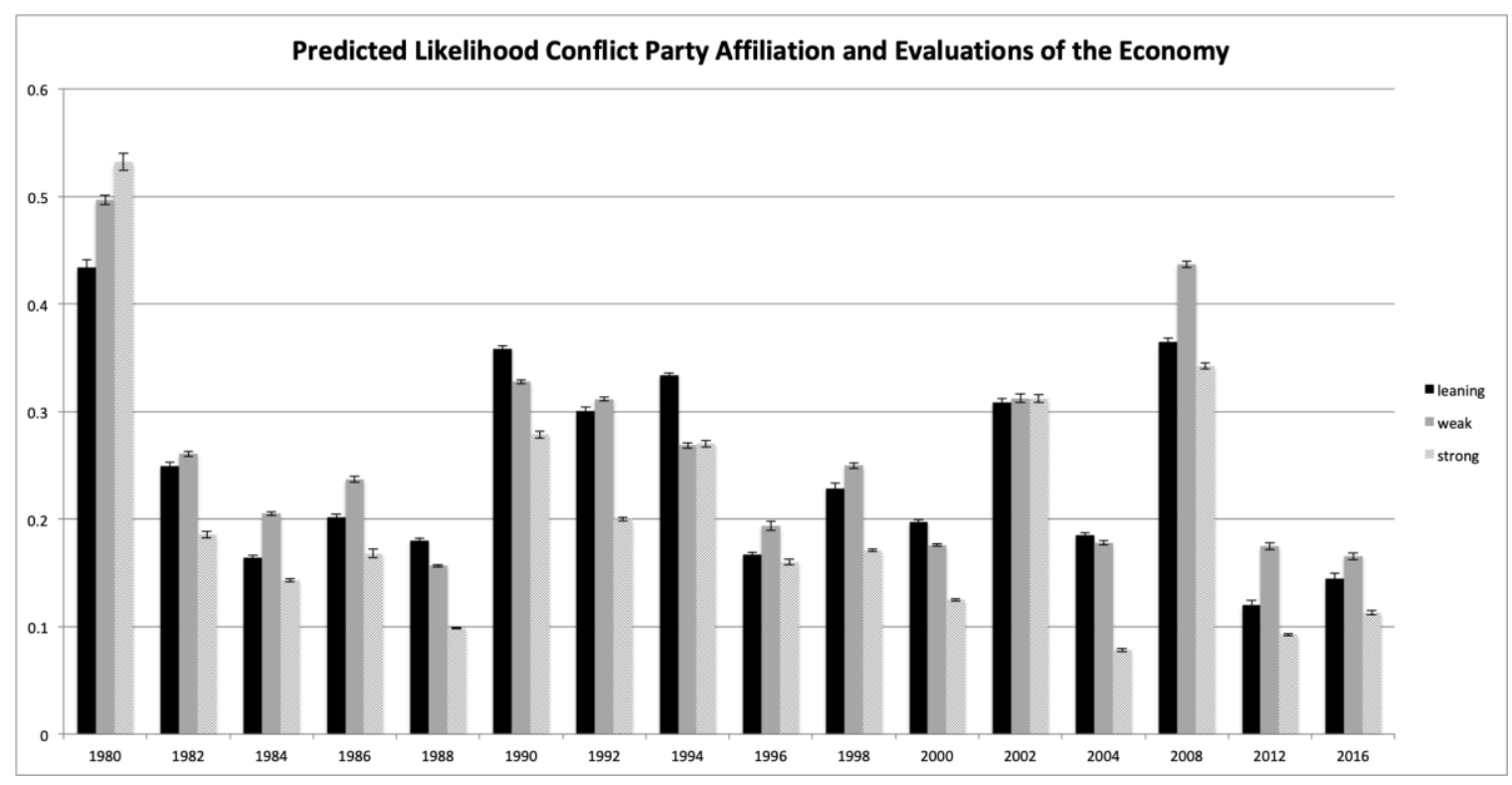

Figure 3 Predicted Likelihood of Conflict Partisans Across Survey Years. Predictions generated using the estimates in Table A2, Model 2, all other variables are set at their mean values. Errorbars represent standard errors 


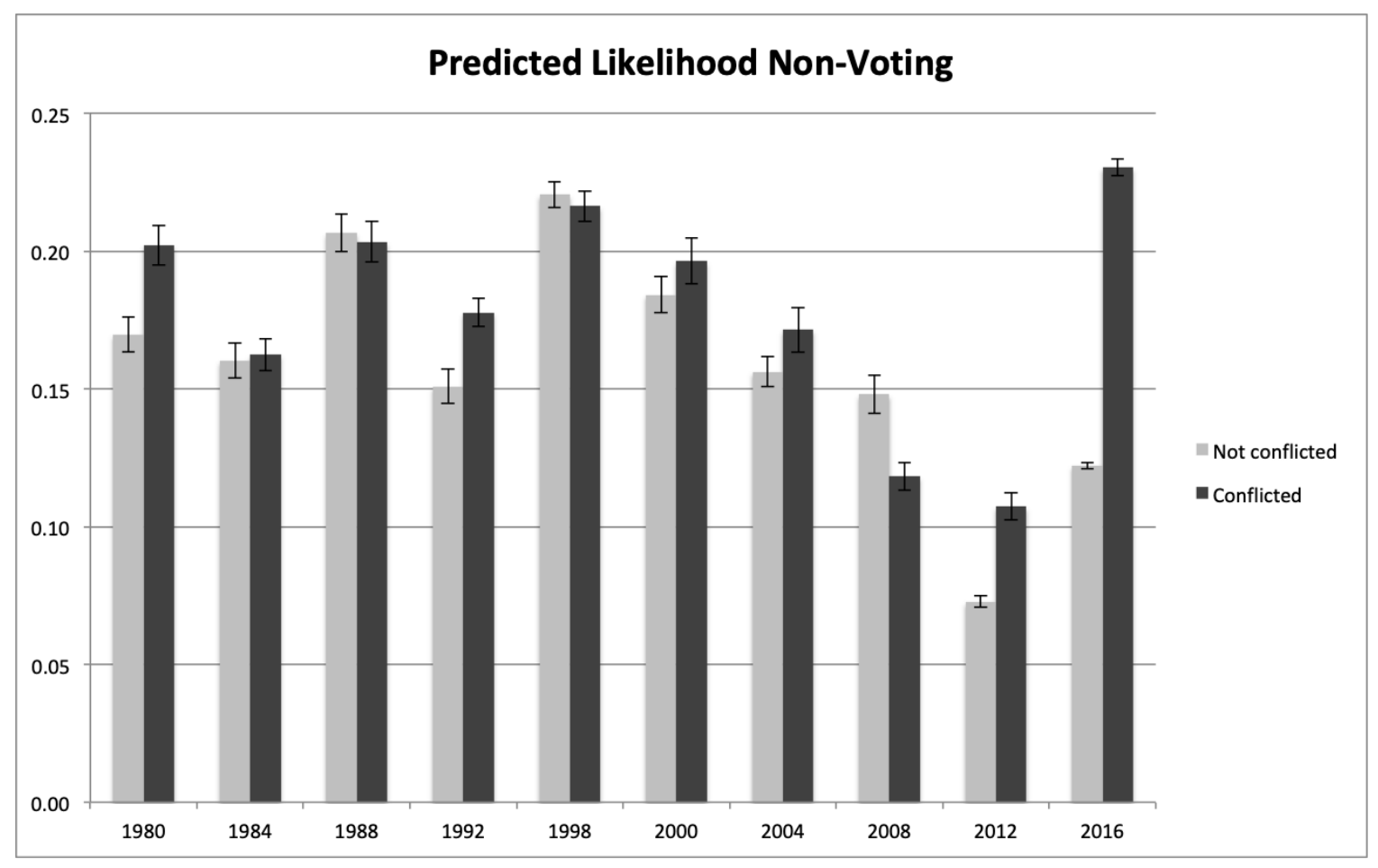

Figure 4 - Predicted Likelihood Non-Voting. Estimates from Table X, Model X all other variables are set at their mean values. Errorbars reflect standard errors

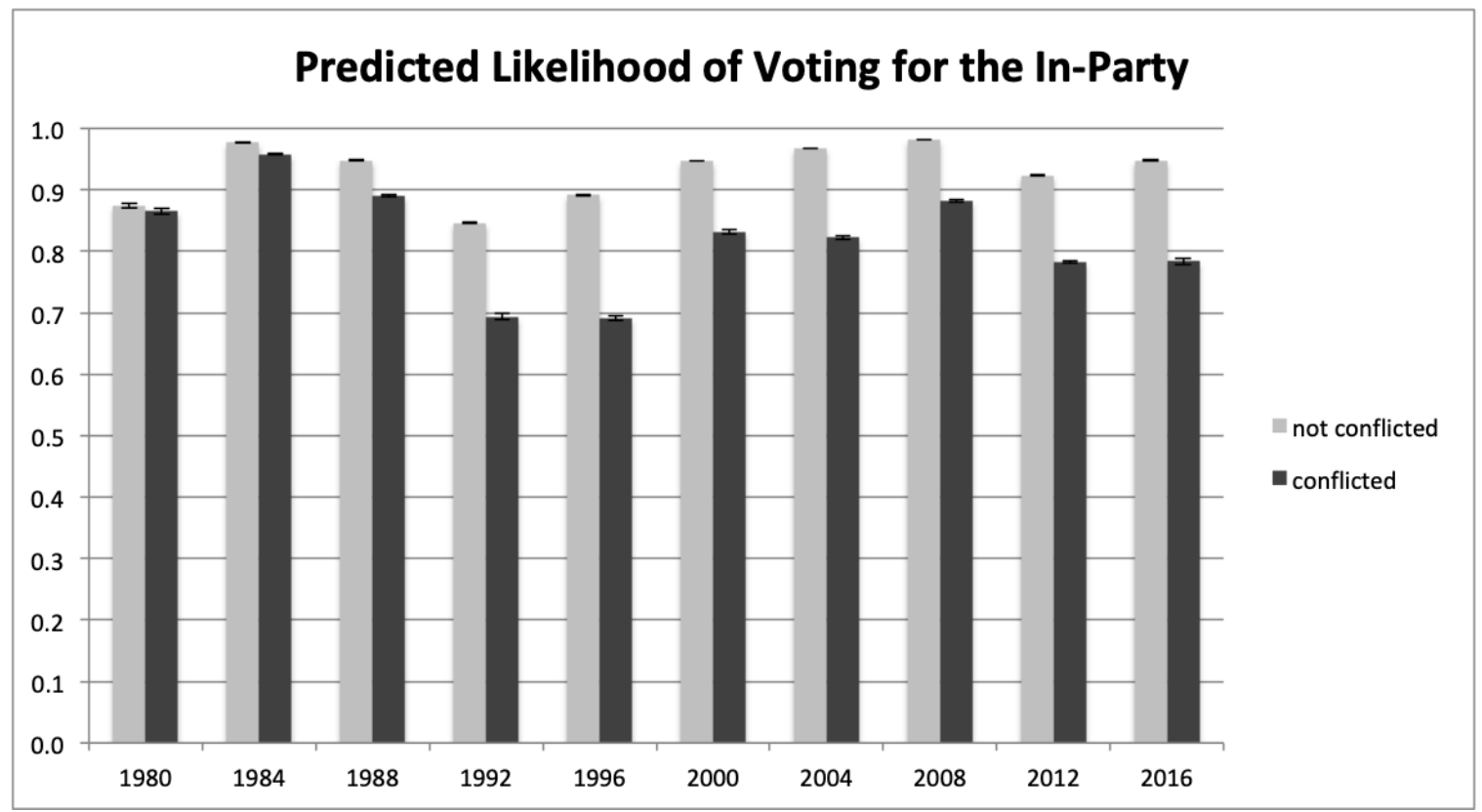

Figure 5 Predicted Likelihood In-Party Vote Conflicted and Non-conflicted Partisans Predictions generated using the estimates in Table A4, Model 2 all other variables are set at their mean values. Error bars represent standard errors. Estimates include partisans with all levels of strength of party affiliation. 
Table 1. Economic evaluations partisan identifiers in 1990-1992 and 2000-2004 panel

\begin{tabular}{l|llll}
\hline \hline Republicans & $\mathbf{1 9 9 0}$ & $\mathbf{1 9 9 2}$ & $\mathbf{2 0 0 0}$ & $\mathbf{2 0 0 4}$ \\
\hline \hline Disapprove & $33.6 \%$ & $54.6 \%$ & $39.7 \%$ & $12.4 \%$ \\
Approve & $62.5 \%$ & $44.1 \%$ & $60.3 \%$ & $87.6 \%$ \\
$\mathrm{DK}$ & $3.9 \%$ & $1.3 \%$ & - & - \\
\hline $\mathrm{N}$ & 304 & 304 & 217 & 217 \\
\hline \hline Democrats & $\mathbf{1 9 9 0}$ & $\mathbf{1 9 9 2}$ & $\mathbf{2 0 0 0}$ & $\mathbf{2 0 0 4}$ \\
\hline \hline Disapprove & $69.4 \%$ & $94.2 \%$ & $3 \%$ & $85 \%$ \\
Approve & $27 \%$ & $5.4 \%$ & $97 \%$ & $15 \%$ \\
$\mathrm{DK}$ & $3.6 \%$ & $0.4 \%$ & - & - \\
\hline $\mathrm{N}$ & 448 & 448 & 303 & 303 \\
\hline \hline
\end{tabular}

Table includes consistent partisan identifiers only, partisans who identified with the same party in both survey waves. ANES 1990-1992 and ANES 2000-2004 panel studies. 